\title{
Bioethics Mediation in Health Care Settings: An Innovative Approach to Shaping Shared Solutions in Ethics Disputes
}

\author{
Efpraxia Avlogiari ${ }^{1}$, Anastasia Konsta $^{2}$, Evanthia Tzitzi $^{3}$
}

\begin{abstract}
${ }^{1}$ Attorney-at-law, MSc in Bioethics, PhDc Medical School in Bioethics Consultation and Mediation, Accredited Mediator \& Mediator Trainer

${ }^{2}$ Professor of Psychiatry, 1st University Psychiatric Clinic of Papageorgiou General Hospital, Faculty of Health Sciences, School of Medicine, Aristotle University of Thessaloniki, Greece

${ }^{3}$ Medical student, Faculty of Health Sciences, School of Medicine, Aristotle University of Thessaloniki, Greece.
\end{abstract}

\begin{abstract}
Bioethics mediation combines the clinical substance and perspective of clinical ethics consultation with the tools of the mediation process, using the techniques of mediation and dispute resolution to help patients, families and healthcare providers enmeshed in conflicts as they wrestle with decisions about life and death. Mediation has long been used to resolve disputes. In the hospital setting, where health care providers faced with intense demands on their time, are called on to explain complex information and deliver bad news to physically and emotionally vulnerable patients and their families and where large number of physicians, nurses and other providers interact with one another and with the patient, it is not surprising that communication breaks down and disputes arise. Bioethics mediation training and services are now available for medical staff conflicts, difficult patient care decisions, employee disputes, medical malpractice claims and bioethics disputes. Bioethics mediation in daily clinical practice. Bioethics Mediation will be patient-oriented and respect the principles and values of both of the two sides of healthcare.
\end{abstract}

Key Words: bioethics, mediation, clinical practice, empathy.

\section{INTRODUCTION}

Scientific and technological medical achievements and the prolongation of human life cause many inconvenient situations which break down the relationship between physicians and patients. These two groups have different perspectives and this difference usually creates physical and emotional stress and makes both sides vulnerable to anxiety, anger, pain, fear, frustration, grief, uncertainty, confusion [1]. Due to the complexity of clinical practice, conflict is everywhere and every time in clinical medicine and not only between physicians and patients but also with providers, administration, payers, and beyond. it has been suggested that moral puzzlements and bioethics conflicts which arise in life and death decisions are really more of a disagreement 
than an ethical dilemma. These bioethics conflicts are almost always about the "proper" and "appropriate" plans for future care; so they are called bioethics or clinical ethics conflicts. It is a common conclusion that most times, bioethics conflicts are caused not from the deficient quality of medical care or the negligent treatment but from absent or ineffective communication. Communication is very important issue. It is an ethical duty in health care setting for every physician and health care provider [2]. In most cases the patients deserve the genuine communication based on trust, honesty and empathy. Ineffective communication plays an important role but it is not the only cause of bioethics conflicts [3]. There is another significant parameter which called moral ambiguity. The philosophical term for the state of moral ambiguity is "aporia" which includes the state of perplexity. In the situation of moral aporia, there is the morally appropriate course of action and a possible consensus among the parties. This happens because all the people who are involved in clinical practice (doctors, nurses, patients, families, government) have their own principles, their unique deeply held values and religious beliefs which affect their lives, their priorities and finally affect their decisions. Despite their difference, all these people want the same thing; for others to respect their values. In clinical ethics, a range of ethical options is acceptable. This creates a pluralism of choices which could satisfy the partners and facilitate agreements on outcomes.

Until now, the Clinical Ethics Consultation (CEC) approach has been defined as a service and is provided by an individual or a consultant team or committee when ethical issues in a clinical case are raised. Its main aim is to enhance the process and outcomes of patient care by helping to identify, analyze and resolve ethical issues [4]. The resolution of ethical problems in the CEC approach is usually a recommendation in a situation of moral aporia. This recommendation is subjective because one set of principles and values is favored over all others and thus it is a single correct resolution. Ethics committees usually reach decisions on a majority vote. They exercise hierarchical authority and unfortunately exclude patients from the decision making process. Experience shows that this way of consulting does not provide desirable results both for physicians and patients. It is necessary to adopt a more effective approach to ethical problems which will be open, collaborative, and transparent and patient-oriented. This is Clinical Ethics Mediation or Bioethics Mediation approach; two terms which are used synonymously. Mediation has long been used to resolve disputes. It is a private, voluntary, informal process in which an impartial third person, the Mediator, facilitates a negotiation between people in conflict and helps them to find proper solutions that meet their interests and needs. In simple words, mediation is a form of assisted negotiation [5]. This process is now used in a variety of medical settings to deal with disputes over Medicare and Medicaid and to resolve medical malpractice claims. Furthermore, mediation tools are being used to aid in disclosure of adverse medical events.

Bioethics mediation is a novel approach for resolving ethical dilemmas which could arise in the daily clinical setting or health care institutions. It uses skills of dispute resolution, emotional intelligence, interpersonal communication and active listening in order to resolve agreements among caregivers, patients and families. The objective is to reach a solution of the dispute which is patient centered and accepted by all the people which are involved. Last but not least, this resolution should comply with the law and the principles of medical ethics. Bioethics mediation is aimed to facilitate a consensual resolution of a dilemma or a shared decision about the best care plan for the patient, while simultaneously respecting patients' needs, rights and cultural values. Bioethics mediation promotes the autonomy of the patients and gives them the opportunity to be heard. Unfortunately, in the context of modern medical facilities, it is common practice for the patients' or their families' voices to be muted, if not lost. Bioethics mediation enhances patients' satisfaction, strengthens their trust and confidence in caregivers, improves the quality of clinical work environment, promotes the positive image of health care institution, prevents legal complications and contributes to risk management. Bioethics mediation is most effective as an intervention method when it is applied as soon as the first sighs of discord appear. Its purpose is to prevent the climaxing of disagreement into conflict and possible litigation. 
In this way it meets the needs of caregivers and patients in helping them deal with ethically charged and emotionally loaded clinical situations [6]. The role of the bioethics mediator is crucial. First, he/she should create a "moral space" in which parties can express thoughts and feelings without fear or judgment regarding issues on which they may have important differences. The bioethics mediator should encourage and permit parties to tell their aspects of the story while minimizing disparities of power, knowledge, skills and experience which separate medical professionals, patients and families. He/she should help patients and families understand the uncertainty that surround diagnosis and treatment. This understanding of uncertainty is a precondition when considering options about care and a critical basis for accepting the outcome, especially if this outcome is death of the patient. Finally the bioethics mediator should ensure that the consensus can be justified as a principled resolution, compatible with the principles of bioethics and the legal rights of patients and families.

A mediative bioethics intervention is a fluid process which is divided artificially into eight stages. It is clear that in real life events never proceed in a predictable and orderly manner. The first stage is about assessing the situation and preparing the mediation with meet with the involved parties together or separately. In the second stage, the mediation is begun. The mediator introduces the patient (stage three), he represents and refines the medical facts (stage four), he gathers information (stage five), he solves the problem (stage six), he reaches a resolution (stage seven) and finally makes a follow-up (stage eight) [7]. Concerning the qualifications which a bioethics mediator should have, these are many and various. First of all, the bioethics mediators should be familiar with the code of medical ethics, with the principles of bioethics as beneficence, non-maleficence, patients' autonomy and social justice, with clinical realities and the knowledge of the attitude and situation of both parties (patients and clinicians). This leads to the fact that bioethics mediator usually could be professionals, members of ethics committees in medical institutional, bioethicists, social workers and medical consultants. Apart from the necessary knowledge, a bioethics mediator should have good communication and interpersonal skills. The necessary communication skills are active listening, non verbal communication, questioning, paraphrasing, reflecting, reframing, summarizing and reality testing. The interpersonal skills are rapport building, demonstrating respect, empathy, authenticity, eliciting the moral view of the involved parties, distinguishing positions from interests and managing the process. The above qualifications are acquired after an intense bioethics mediation training program in order that the bioethics mediators be effective to manage conflicts which are caused from communication breakdowns, cultural differences, disparate value systems and ethical dilemmas.

\section{CONCLUSION}

Scientific and technological medicine achievements and the prolongation of human life cause many inconvenient situations which can break down the relationship between physicians and patients. The amount of disappointed patients and frustrated physicians in combination with increased lawsuits against healthcare providers require the incorporation of Bioethics Mediation in daily clinical practice. Bioethics Mediation will be patient-oriented and respect the principles and values of both of the two sides of healthcare. Thus, this new manner of consultation could reduce physical and emotional stress between patients and physicians, helping both sides handle difficult situations more efficiently and improving the quality of healthcare.

\section{REFERENCES}

1. Kranidiotis C, Gerovasilis B, Tasoulis A, Nana S. End-of-life Issues in Intensive Care Unit,, p. 19, Nanas. Stroke Death, Scientific Review, Stamoulis. 2006.

2. Lester GW, Smith SG. Listening and talking to patients. A remedy for malpractice suits?. West J Med 1993;158(3):268-72 
3. Levinson W, Roter DL, Mullooly JP, Dull VT, Frankel RM. Physician-patient communication. The relationship with malpractice claims among primary care physicians and surgeons. JAMA 1997;277(7):553-9

4. Dubler NN, Webber MP, Swiderski DM; Faculty and the National Working Group for the Clinical Ethics Credentialing Project. Charting the future. Credentialing, privileging, quality, and evaluation in clinical ethics consultation. Hastings Cent Rep 2009;39(6):23-33.

5. Beer JE. Stief E. The Mediator's Handbook. New Society Publishers ; 1997.

6. Shalev C. Resolving ethical dilemmas in clinical medicine. http://www.imed.ac.at/ethucation/Veranstaltungen/bioethics_mediation_workshop_informatio n.pdf

7. Liebman C, Dubler N. Bioethics Mediation: A guide to Shaping Solutions. United Hospital Fund : New York ; 2010.

$* * * * * * * * * * * * * * * * * * * * * * * * * * * * * * * *$

This manuscript was presented as part at the UNESCO Chair in Bioethics $12^{\text {th }}$ World Conference, March 21-23, 2017

\author{
Acknowledgements - Nil \\ Source of Funding - Nil \\ Conflict of Interest - Nil
}

